\title{
Network dynamics of Chinese university knowledge transfer
}

\author{
Yindan Ye ${ }^{1,2,3} \cdot$ Kevin De Moortel ${ }^{1} \cdot$ Thomas Crispeels $^{1}$
}

Published online: 1 August 2019

(C) The Author(s) 2019

\begin{abstract}
Social networks are increasingly considered to be influential in explaining the knowledge transfer process. Despite scholarly efforts to integrate knowledge transfer and social network research, we lack understanding on how knowledge transfer networks emerge and evolve. We draw upon resource dependency theory and inter-organizational networks and collect patent data of 42 Double-First Class (DFC) universities to study structural properties of the Chinese university knowledge transfer network over time. Our results point to the existence of an increasingly complex yet remarkably efficient network. Universities and co-patent collaborations emerge in the network and act as knowledge bridges between other universities. The network moves from an early-stage single-centered network to a mature multi-centered network through a power-law pattern. Such movement allows for an aggregation phenomenon to appear as oligopolistic communities emerge and rule the network. While knowledge is more easily shared and accessible within communities, their existence also brings along control over knowledge bases embedded in those communities. Key universities take central positions within the expanding network, which allows them to gain control and easier access to knowledge. It also hints that it might be difficult for other DFC universities to become key players in the network. On an inter-regional level, our findings point to steadily increasing knowledge transfer activity, which is key to overcome the underdevelopment of some Chinese regions. Overall, this paper contributes to our understanding on the theoretical connection between knowledge transfer and social network dynamics, on how universities evolve through knowledge transfer networks, and on how their embeddedness translates into knowledge control, knowledge access, and knowledge bridges.
\end{abstract}

Keywords Knowledge transfer $\cdot$ Network dynamics $\cdot$ University $\cdot$ China

Yindan Ye

yindan.ye@vub.be; yeyindan@163.com

Kevin De Moortel

Kevin.De.Moortel@vub.be

Thomas Crispeels

Thomas.Crispeels@vub.be

1 Department of Business Technology and Operations, Vrije Universiteit Brussel, Brussels, Belgium

2 School of Statistics, Renmin University of China, Beijing, People's Republic of China

3 Institute of International Finance, Bank of China, Beijing, People's Republic of China 
JEL Classification O33 $\cdot$ R11

\section{Introduction}

Knowledge transfer includes all activities related to the transfer of knowledge and capabilities developed inside universities to non-academic environments (Molas-Gallart and Sinclair 1999), and is globally considered the third mission of universities, next to teaching and research (Philpott et al. 2011). As engines of innovation, universities transfer knowledge through several mechanisms, including publications, patents, consulting, informal meetings, recruiting, licensing, joint ventures, research contracts, and personal exchanges (Agrawal 2001). Among these mechanisms, patents are visible indicators of technological change and innovation and form an important commercialization channel (Kroll and Liefner 2008; Meyer-Krahmer and Schmoch 1998).

Social networks are increasingly considered to be influential in explaining the process of knowledge transfer (Phelps et al. 2012; Borgatti and Foster 2003). Indeed, knowledge production and transfer, which are central to explaining economic growth, increasingly rely on social networks (Powell and Grodal 2005; Romer 1990; Seck 2012). From a network perspective, knowledge transfer refers to the effort of a source to share knowledge with a receiver and the receiver's effort to acquire and absorb this knowledge. In such a perspective, patents serve as conduits for the transfer of information and knowledge (Belderbos et al. 2014). The use of social network theories and methods within knowledge transfer literature has resulted in significant contributions. These contributions focus on the determinants of network formation and its properties (e.g. Breznitz et al. 2018; Fernández-Olmos and Ramírez-Alesón 2017; Huggins et al. 2019; Mitze and Strotebeck 2019; Morescalchi et al. 2015) or the effect of knowledge transfer networks on economic growth or innovation performance (e.g. Seck 2012, Guan et al. 2015; Jiang et al. 2017; Scuotto et al. 2017; Xu et al. 2019; De Noni et al. 2018).

Despite these efforts to integrate knowledge transfer and social network research, we still lack understanding on several aspects (Ahuja et al. 2012; Phelps et al. 2012; Zaheer et al. 2010; Battistella et al. 2016). In particular, scholars increasingly question the dynamics of a social network, i.e. how and why networks emerge and evolve (Ahuja et al. 2012), a question which remains underexplored in inter-organizational knowledge transfer research (Giuliani 2013; Noh and Lee 2019). Taking into account the gradual move towards universities as key actors in transferring knowledge to society, we construct a university knowledge transfer network and track its evolution and the position of key universities within the network over time. In contrast to existing studies that rely on social networks as a theoretical basis, we analyze the network's structural properties through a multi-level social network approach. However, we draw upon the resource dependency theory to explain knowledge transfer collaborations. In doing so, we increase our understanding on how universities access knowledge through networks and on how universities control and maintain knowledge collaborations (Borgatti and Foster 2003).

While literature has mainly focused on developed countries as an empirical setting (e.g. De Prato and Nepelski 2012; Protogerou et al. 2013; Töpfer et al. 2017), we lack understanding on the evolution of knowledge transfer networks in developing countries (Cunningham and O'Reilly 2018; Wang et al. 2015b; Yang et al. 2019). China aims to transfer itself from an imitation-based to an innovation-based economy and considers knowledge transfer an important vehicle to this end (Fisch et al. 2016). The "Chinese Bayh-Dole Act" 
brought along a surge of Chinese patent applications and Chinese university patent applications (Hong 2008; Wang et al. 2015b). Amongst other innovation promotion strategies and policies, the "Double-First Class Plan" (DFC plan) issued by the Ministry of Education (MOE) in 2017 targets the top 42 Chinese universities and aims to further promote university quality and knowledge transfer in China. We use patent application data of these 42 top Chinese universities from 2004 till 2014. As we study the Chinese university knowledge transfer network, we add insights to the discussion on inter-regional knowledge transfer as a means to improve innovation capabilities of less favored regions (e.g. Gao et al. 2011).

\section{Resource dependency theory and social network analysis}

In a knowledge transfer context, we define a network as a set of heterogeneously distributed knowledge repositories or actors (nodes) that create, search for and transmit knowledge, interconnected by social relationships (ties) that enable or constrain the nodes' effort to transfer knowledge (Phelps et al. 2012). In our study, the nodes are represented by universities and the organizations that collaborate with universities. The co-patenting behavior of the universities and organizations represent the relationships; one joint patent thus reflects one relationship. We refer to the resulting social network as university knowledge transfer networks. Social network scholars differentiate between three levels of analysis: interpersonal, inter-organizational, and intra-organizational levels (Phelps et al. 2012). As we consider universities as our units of analysis, acting as key engines of innovation and important sources of new knowledge (Agrawal 2001; Siegel et al. 2003), our study falls within the inter-organizational level.

Inter-organizational networks have received attention through different theoretical lenses, e.g. institutional, agency, contingency, bargaining... (Oliver and Ebers 1998). In particular, resource dependency theory, social network theory, and their combination have been frequently used to explain the phenomenon. Resource dependency theory investigates the process through which organizations reduce their environmental dependencies by using various strategies that enhance their power within inter-organizational systems (Pfeffer and Salancik 1978). Social network theory is concerned with how the position of actors within a network of relations, and the content of these relations, affect their opportunities for actions (Burt 1992). However, when it comes to inter-organizational knowledge transfer networks, one should not overlook that social networks by themselves do not suffice as a theoretical base (Zaheer et al. 2010). Rather it suggests that structure matters, but it is incumbent on the researchers to explain the underlying causal knowledge transfer processes through interpretation of the results. Therefore, in this study, we view social networks as a methodology and draw upon the resource dependency theory to explain knowledge transfer collaborations.

The foundation of resource dependency theory connects to social capital theory (Borgatti and Foster 2003), which links one's ties or network position to outcomes such as power, leadership, mobility, employment, or performance. In a knowledge transfer context, the resource at stake is knowledge, which may be transferred between members of a network (Zaheer et al. 2010). Each member of the network acts as a knowledge resource itself-by providing knowledge to another member-and/or acts as a conduit through which other members access knowledge (Zaheer and Bell 2005). The transfer of knowledge between members serves as knowledge procurement strategy-since no organization is able to know or do everything on their own-and as uncertainty reduction mechanism 
(Gulati and Gargiulo 1999; Yang et al. 2019). Members of a knowledge network are able to access knowledge that is difficult to obtain otherwise and, in doing so, enhance their own position and power within the network (Borgatti and Foster 2003). By adding a time dimension to this logic, the inter-dependence on knowledge between members changes over time (Ahuja et al. 2012) and the knowledge that members accumulate over time represents a resource that they can exploit or subsequently draw on (Nahapiet and Ghoshal 1998; Soda et al. 2004).

This paper focusses on patents as a mechanism for knowledge transfer (Belderbos et al. 2014). Depending on the data used, patent-based knowledge transfer research falls into three categories: patent citation (e.g. AlAzzawi 2011; Ribeiro et al. 2014; Tijssen 2001; Ye et al. 2015), patent licensing (e.g. Yang et al. 2019), and patent co-ownership research (e.g. Choe and Lee 2017; Li et al. 2014). Patent citation data is unable to distinguish important knowledge flows from prior patents that may or may not affect the invention of the citing patent (Henderson 2007). The use of patent licensing data is also limited as official registers of patent licenses are recorded on a voluntary basis and therefore may not cover a complete picture of a country's licensing activities (Yang et al. 2019). Compared to such data sets, joint patent data is more likely to reflect real interactions and knowledge flows among patent owners. However, as it represents undirected knowledge flows, we ought to adjust our network measurements to take this limitation into account.

From a resource dependency perspective, organizations typically face internal knowledge constraints. In that regard, co-ownership of intellectual property is a relevant strategy to co-develop knowledge since they serve as conduits for passing on that knowledge (Zaheer et al. 2010). Co-patents, patents owned by two or more assignees, tend to receive higher patent citations and co-patents in which a university is involved tend to be associated with higher market value (Belderbos et al. 2014). A key assumption in using co-patents as knowledge transfer mechanism is that organizations listed on the same patent know each other, have collaborated, and thus have exchanged knowledge (Gao et al. 2011). Also, taking into account the time dimension, two organizations who worked together on at least one patent are able to get in touch again or share knowledge directly or indirectly more easily compared to disconnected organizations (Singh 2005).

The majority of the work on inter-organizational networks has concerned itself with how and why organizations collaborate with other organizations (Borgatti and Foster 2003; Zaheer et al. 2010). Such concerns are typically addressed through a structuralist or connectionist lens, in which structuralists focus on the configuration of ties in the network, while connectionists focus on the content of the resources that flow through these network ties (Borgatti and Foster 2003; Mayhew 1980). We put ourselves in the structuralist camp, and investigate the structural properties of university knowledge transfer networks: (1) the location of a node relative to others (network position), (2) the pattern of ties within a node's immediate set of contacts (node network structure), and (3) the pattern of ties among all nodes in bounded population (whole network structure) (Phelps et al. 2012). The network positions of nodes allow us to identify the more prominent, i.e. more important, universities within the university knowledge transfer network (Zaheer et al. 2010). The node network structure reflects the collaboration intensity of a university within its network and thus reflects the amount of knowledge sharing within the university knowledge transfer network (Ahuja et al. 2012). Node network structure allows us to say something about how efficient knowledge flows through the university knowledge transfer network. Whole network structure reflects the connectivity within the network and allows us to identify cohesive groups or clusters within the university knowledge transfer network. 


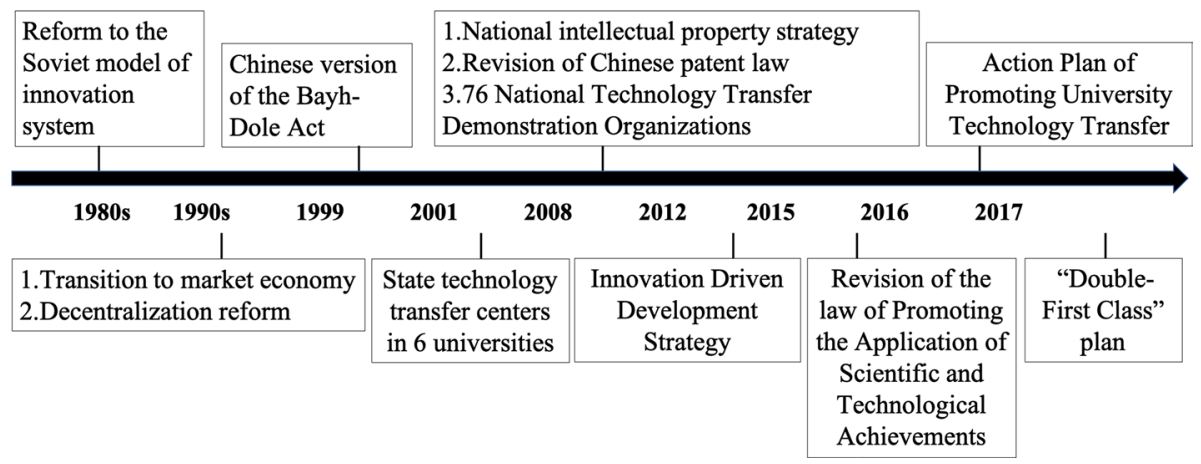

Fig. 1 China's innovation and technology transfer-related policies since the 1980s (Source: own set-up)

\section{Background: Chinese university knowledge transfer}

Around the world, governments implemented regulations to facilitate knowledge transfer (Fisch et al. 2015; Wang et al. 2015a). In Fig. 1, we provide an overview of the implementation of China's innovation and technology transfer policies. The 1980s was a time of several important reforms as China transformed its national innovation system to comply with the Soviet innovation system (Fong et al. 2018; Liu and White 2001; Wang et al. 2015a). Chinese universities were given greater autonomy in managing their research activities, and interactions with industry were encouraged (Motohashi and Yun 2007). The transition from a planned economy to a market economy, institutional mergers and weakened ministry control over universities and industry led to the decentralization reforms of the 1990s (Zhou et al. 2003). In 1999, the Ministry of Education (MOE) issued a Chinese version of the Bayh-Dole Act, allowing universities to retain ownership of research results obtained with governmental funding, which laid the foundation for the protection and commercialization of university intellectual property (IP). In 2001, the State Economic and Trade Commission and MOE jointly established state technology transfer centers in six universities (Wu 2010). By improving the performance of Chinese university knowledge and technology transfer through several programs, the Chinese government recognized innovation and knowledge transfer to be the engine of economic development and considers Chinese universities as key actors in China's transformation (Hong 2008; De Moortel and Crispeels 2018).

A next milestone in China's innovation strategy occurs in 2008. The Chinese national government implemented its IP strategy to enhance IP creation, application, protection and management, in an effort to increase autonomous innovation capabilities. The Chinese patent law was revised to strengthen the protection of IP rights and to encourage and promote technological innovation. The Ministry of Science and Technology (MOST) selected 76 organizations to be National Technology Transfer Demonstration Organizations. Today, there are 453 such organizations. ${ }^{1}$ In 2012, China launched its Innovation Driven Development Strategy, which advances innovation as a national strategy. In 2015, the Law of Promoting the Application of Scientific and

\footnotetext{
${ }^{1}$ http://www.chinatorch.gov.cn.
} 
Technological Achievements, originally launched in 1996, was revised to encourage $\mathrm{R} \& \mathrm{D}$ organizations and universities to transfer technologies to enterprises. To improve China's higher education quality and further promote university knowledge transfer, the MOE issued the Action Plan of Promoting University Technology Transfer in 2016 and the "Double-First Class" plan (DFC plan) in 2017. The DFC plan targets 42 Chinese universities across 31 provinces and aims to transform these into 42 world-class universities. The DFC universities receive additional government funding for R\&D and teaching.

Over the past 15 years, the number of patent applications, especially domestic applications, grew quickly with an average growth rate of $23.91 \%$. Chinese university patenting activity increased due to patents being an important criterion in university evaluations by the MOE and the surge of intense top-down government innovation policies to meet international patent standards (Henderson et al. 1998; Luan et al. 2010; Thursby et al. 2001; Wang et al. 2015a). In 2011, China became the top country in terms of number of patent applications with over 56 million patent applications (Fong et al. 2018).

The fast growth in Chinese patent applications translates into different knowledge transfer patterns in China (Gao et al. 2011). China majorly relies on intraregional and international collaborations, while inter-regional knowledge transfer is relatively weak. Liang and Zhu (2002) and Wang et al. (2005) note that the lack of inter-regional knowledge transfer activity results from geographical distances still being a major obstacle for technological and scientific collaborations in China; a situation similar to that in other countries (Spithoven et al. 2019). However, inter-regional knowledge transfer deserves particular attention as it plays an important role in improving Chinese regions' innovation capabilities and technological progress-particularly of less favored regions (Yang et al. 2019). Indeed, although China's overall innovation capability has improved, innovation capabilities, R\&D resources, and technology transfer performance vary across China's eastern, central, and western areas due to uneven economic development ( $\mathrm{Li}$ et al. 2010). The eastern coastal provinces, especially those in the Yangtze River Economic Circle, the Pearl River Economic Circle, and the capital city of Beijing, are considered to be the most innovative areas in China (Liu and Sun 2009). As an indication, the total amount of patent applications originating from these three areas constituted $48.22 \%$ of the total amount of patent applications in 2015 .

\section{Data and methodology}

We analyze the Chinese university knowledge transfer network's structural properties on three levels: the whole level, the community level, and the node level (Fig. 2). At the whole network level, we apply classical network measures to analyze structural properties and behavior of the entire network over time (Zaheer et al. 2010). Communities are groups or clusters of organizations that follow a certain classification. We apply a community detection method to detect communities within the network and analyze the features and evolution of these communities. At the node level, we turn to classic position measures to capture the position of universities in the network, recognize key universities based on their positions, and track the evolution of university positions in the network. We analyze interregional collaborations between universities in the network to address and further investigate a key impediment in Chinese knowledge transfer. 
Whole network level

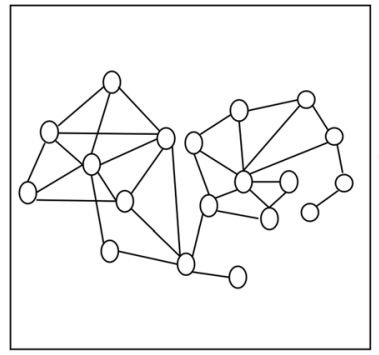

Network level analysis

1. Network features

2. Network evolution
Community level

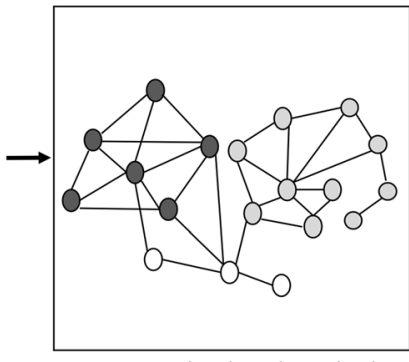

Community level analysis

1. Community detection

2. Community evolution
Node level

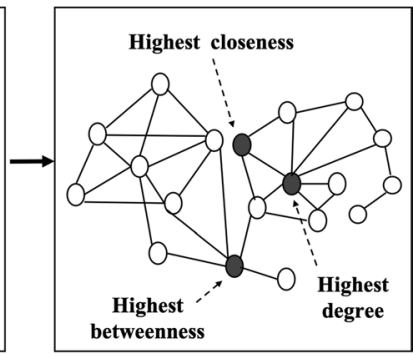

Node level analysis

1. Node's position evolution

2. Key nodes evolution

3. Cross-regional analysis

Fig. 2 Chinese university knowledge transfer network analysis framework (Source: own set-up)

\subsection{Data}

Researchers consider patents to be valuable mechanisms for knowledge transfer. On top of this, patent data is easily accessible and provides systematically recorded details on inventors, organizations, and locations (Agrawal and Henderson 2002). As such, patents allow for more comprehensive analysis, compared to surveys or case studies (Henderson et al. 1998). In China, patents are granted by the State Intellectual Property Office (SIPO) and are divided into invention patents, utility model patents, and design patents (Wu 2010). Invention patents cover "new technical proposals on products, methods, or both"; utility model patents cover "new technical proposals on shape, structure of a product or the combination of both"; and exterior design patents cover "aesthetics and industry-applicable new designs for shape, design or color of a product, or their combination" (Sun 2000, p. 443). We focus on invention patents and utility model patents, as they concern technical proposals and innovations, while exterior design patents mainly concern aesthetic improvements. Among all domestic patent applications since 2000, the average annual growth rates of invention and utility model patents have been $29.66 \%$ and $21.56 \%$ respectively. ${ }^{2}$

This paper considers Chinese universities are vanguards of China's innovation reform. Compared to other organizations, universities are more creative and are the impetus for innovation. From 1986 to 2016, among all the patents applied for by universities and colleges, the proportion of invention patents was $60.48 \%$, while the average proportion of invention patents applied by all organizations was only $31.04 \%$.

DFC universities are the most innovative universities in China. Their patent network represents core knowledge flows of Chinese universities. We downloaded invention and utility model patent applications of 42 DFC universities from the Espacenet database ${ }^{3}$ in November 2017. We made sure that at least one of the applicants is one of the 42 DFC universities. We retrieved 539,329 patent applications with a publication date between January 1, 2004 and October 31, 2017. Since, for invention patents, it can take up to 35 months

\footnotetext{
${ }^{2}$ China Statistical Yearbook: 2001-2017.

${ }^{3} \mathrm{https}: / /$ worldwide.espacenet.com.
} 
between application and publication date, we mitigated the potential time lag bias by withholding patent applications filed before December 31, 2014.

We filtered out solo patents, duplicates, and patents that do not include one of the 42 DFC universities as an applicant. As we focus on the inter-organizational level of analysis, we considered university-affiliated institutions (schools, faculties, hospitals, etc.) to be part of one organization. We applied the same logic to companies and their subsidiaries, branches, and affiliated institutions. Some patents are jointly applied for by individuals and organizations. For these patents, we deleted the names of the individuals, as we consider individual applicants as members of the applicant organizations. Finally, we retained 21,612 joint patent applications.

\subsection{Methodology}

In line with our three-leveled analysis, in this section we clarify the whole network level measures, the community detection measures, and node level measures used in this study. To account for the time dimension, we measure the evolution of the network properties at each level over time. We visualize each year's university knowledge transfer network and observe its evolution. We additionally test the growth pattern of the network and question the constant average degree assumption that the number of ties grows linear with the number of nodes (Leskovec et al. 2005), which is widely adopted in recent network evolution models. Next to this three-leveled analysis, due to an increased attention to the less favored Chinese regions, we capture inter-regional knowledge transfer dynamics with a separate measure.

Since we use joint patent application data, our university knowledge transfer network forms an undirected network, i.e. the ties between the nodes are undirected. As such, there is no difference between a tie from node $\mathrm{A}$ to node $\mathrm{B}$ and a tie from node $\mathrm{B}$ to node A. All measures in this paper are adapted towards the characteristics of undirected networks. We use the igraph package in R to calculate the network measures (Csardi and Nepusz 2006). We include names and definitions of all variables in "Appendix A".

\subsubsection{Whole network measures}

To capture whole network structural properties, we use transitivity, density, shortest path, and (effective) diameter measures. By analyzing these measures, we are able to analyze how efficient knowledge flows through the university knowledge transfer network and how organizations access new knowledge in the network.

Transitivity, i.e., the clustering coefficient, is a measure of the extent to which nodes tend to cluster together in the network. In this paper, we use a global transitivity measure for the network's overall clustering status. The calculation of a global transitivity measure is based on triplets of nodes. A triplet represents three nodes that are connected by either two (open triplet) or three (closed triplet) undirected ties. For undirected networks, the global transitivity is equal to the number of closed triplets over the total number of open and closed triplets (Wasserman and Faust 1994). A higher transitivity implies more closed triplets in the network and more direct ties between organizations. Thus, a higher transitivity eases an organization's access to knowledge in the network.

The density of a network measures a network's complexity and compactness. It is the ratio of the number of ties and the maximum possible number of ties in the network (Wasserman and Faust 1994). Mathematically, Density equals $\mathrm{E} /[0.5 \times \mathrm{N} \times(\mathrm{N}-1)]$, in which 
$\mathrm{E}$ is the total number of real ties, $\mathrm{N}$ is the number of nodes, and $0.5 \times \mathrm{N} \times(\mathrm{N}-1)$ is the maximum possible number of ties in the network with $\mathrm{N}$ nodes. Increased density indicates increased efficiency of knowledge flows and easier access to new knowledge for organizations in the network. In general, since the growth rate of $\mathrm{E}$ is slower than the growth rate of $\mathrm{N}^{2}$, the density of a large-scale network is smaller than the density of small-scale networks.

A path in a network is a sequence of incident ties. The shortest length of a path is the number of ties the shortest path contains, i.e. the minimum number of steps needed for one node to reach another. We denote the shortest path length between node $i$ and node $j$ as $l_{i j}$. The average shortest path length $(\bar{l})$ is defined as the average number of steps along the shortest paths for all possible pairs of nodes in the network. It is a measure of the efficiency of knowledge flow in a network. If two nodes in the network are not able to reach each other, i.e. their shortest path length is infinity, the nodes are not considered in the calculation of average shortest path length to avoid calculations that include infinite numbers.

The network diameter represents the linear size of a network. It equals the longest shortest path in the network, i.e. shortest path length between the two most distant nodes in the network (Newman 2003; Wasserman and Faust 1994). In reality, a network is not always fully connected; some nodes do not tie to any other nodes. In order to avoid an infinite diameter, only the largest connected component of the network is considered in the calculation of the diameter. The effective diameter represents a smoothed diameter and is considered to be more robust as a measure. The most commonly used effective diameter in network analysis is the 90th percentile effective diameter, which equals the number of ties needed on average to reach $90 \%$ of all other nodes (Leskovec et al. 2005). The effective diameter and diameter tend to exhibit qualitatively similar behavior.

\subsubsection{Community detection measures}

No consensus exists on a precise definition of a community. One of the most widely accepted definitions is from Newman and Girvan (Newman and Girvan 2004). They define a community as a subnetwork containing nodes which are more densely tied to each other than to the rest of the network. Or equivalently, a network has a community structure if the number of ties into any subnetwork is higher than the number of ties between those subnetworks. Within a community, knowledge is more easily accessible to the members of that community and typically communities have a certain control over stocks of knowledge.

Community detection is the process of discovering communities in networks and is widely used in network analysis (Bedi and Sharma 2016). We use the walktrap algorithm (Pons and Latapy 2005) to detect communities in the university knowledge transfer network. The walktrap algorithm uses a distance measure based on random walks through the network and applies a hierarchical agglomerative clustering approach (Pons and Latapy 2005). As the name suggests, a walker on one node randomly and uniformly moves to a subsequent node among its neighbors. The idea behind this algorithm is that the walker tends to become trapped in a community and that short random walks tend to stay within the same community.

We apply the Wilcoxon rank-sum test to test the significance of the communities detected. The Wilcoxon rank-sum test considers the "internal" and "external" degrees of a community in order to quantify its significance. We denote the ties within a community as "internal" ties and the ties connecting the nodes of a community with the rest of the network "external" ties. The null hypothesis of this test is that there is no difference between the number of "internal" and "external" ties linked to a node of the 
community. In contrast, a higher amount of internal ties than external ties indicates that a community is significant; while the inverse indicates that the community is in fact an "anti-community".

\subsubsection{Node level measures}

Centrality is the most important and commonly used measure to reflect the position and power of nodes in networks. The position of a node within the university knowledge transfer network over time reflects the changes in the amount of accessibility or control that a node has over the knowledge available in the network. Among all centrality measures, degree, closeness and betweenness are most commonly used (see Fig. 2). Node $i$ in the network is denoted as $n_{i}$, and its degree, closeness and betweenness are denoted as $C_{D}\left(n_{i}\right), C_{C}\left(n_{i}\right)$ and $C_{B}\left(n_{i}\right)$. To maintain comparability across different networks over time, we calculate a node's normalized degree $C_{D}^{\prime}\left(n_{i}\right)$, closeness $C_{C}^{\prime}\left(n_{i}\right)$, and betweenness $C_{B}^{\prime}\left(n_{i}\right)$ :

Degree counts the number of ties a node possesses (Freeman 1978). The degree of node $i$ is $C_{D}\left(n_{i}\right)=e\left(n_{i}\right)$, where $e\left(n_{i}\right)$ is node's $i$ number of ties. Normalized degree $C_{D}^{\prime}\left(n_{i}\right)=C_{D}\left(n_{i}\right) /(N-1)$, where $N$ is the total number of nodes in the network. A node's degree indicates how many direct collaborations it has and it reflects its importance in the network and its access to other resources. The more ties a node has, the more important it is considered, the more knowledge it possesses and the easier it can access knowledge held by other nodes. We use a distribution of all node degrees in the network to measure the distribution of knowledge in the network.

Closeness is based on the sum of the length of the shortest paths between the node and all other nodes in the network (Bavelas 1950). The closeness of node $i$ is calculated as $C_{C}\left(n_{i}\right)=\left[\sum_{i, j} l_{i j}\right]^{-1}$, where $l_{i j}$ is the shortest path length between node $i$ and $j$. Normalized closeness is then calculated as $C_{C}^{\prime}\left(n_{i}\right)=C_{C}\left(n_{i}\right) /(N-1)$. The higher the value of normalized closeness, the more centrally positioned that node is, which reflects easier access to knowledge held by other nodes in the university knowledge transfer network.

Betweenness centrality for a node in a network equals the number of shortest paths between two other nodes that pass through that one node. It calculates the node's presence on the shortest paths of other nodes' pairs. We denote the number of shortest path between node $j$ and $k$ as $g_{j k}$ and the number of nodes $j$ and $k$ 's shortest paths which go through node $i$ as $g_{j k}\left(n_{i}\right)$. Then, $C_{B}\left(n_{i}\right)=\sum_{k=1}^{N} \sum_{j=1}^{N} g_{j k}\left(n_{i}\right), j \neq k \neq i, j<k$. Normalized betweenness is calculated by $C_{B}^{\prime}\left(n_{i}\right)=2 C_{B}\left(n_{i}\right) /[(N-1)(N-2)]$. In networks, betweenness represents a node's power by having control over the network. When a node has a higher betweenness, more knowledge will flow through it (Freeman 1977).

\subsubsection{Inter-regional knowledge transfer measure}

In order to gain insight into inter-regional university knowledge transfer activities, we group the universities based on their region and calculate the minimum steps required for universities in one region to reach universities in another region. According to the National Bureau of Statistics of People's Republic of China, the 42 universities are located in 24 different regions, with 22 universities in East China, seven in Central China, four in Northeast China, and nine in West China. 


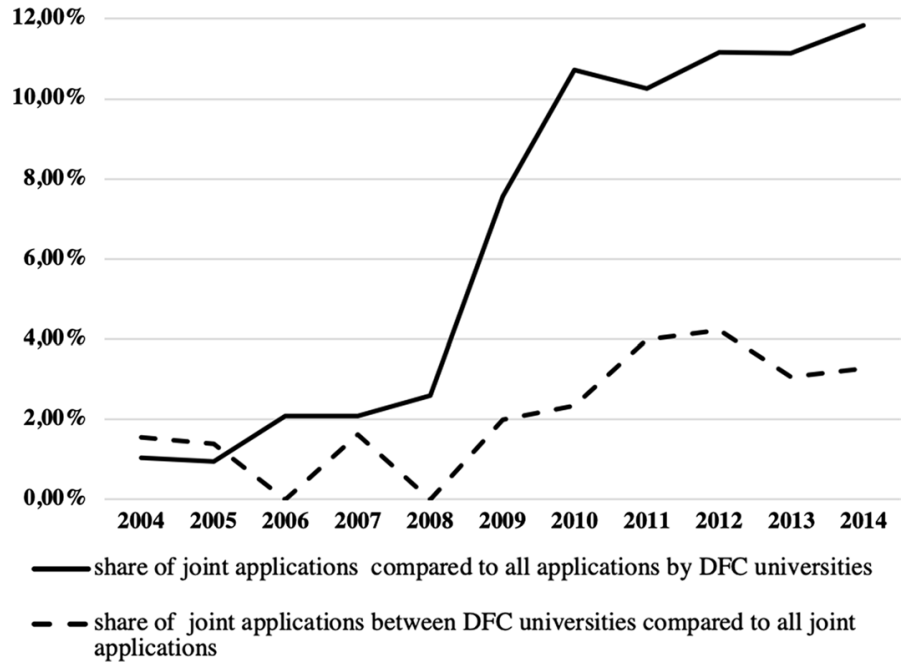

Fig. 3 Patent collaborations of DFC universities (Source: own set-up)

\section{Data analysis and results}

\subsection{Patent applications of Chinese universities}

In line with the rise of patent activity in China, the total amount of patent applications of the 42 DFC universities has grown quickly since 2008 . However, the growth rate decreases from $37.49 \%$ in 2008 to $9.30 \%$ in 2014 . While the rise of joint patent applications is notably smaller compared to the rise of total patent applications, the percentage of joint applications increases from $2.6 \%$ in 2008 to near $12 \%$ in 2014 (Fig. 3). The percentage of intergroup applications, i.e. patent applications between the 42 DFC universities, remains low and even declines in 2012; we note that the 42 DFC universities increasingly collaborate with partners outside the DFC group.

Next to the trend of overall increased patenting activity, we observe a strong growth in the patenting activity of less-experienced Chinese universities (Table 1). The rate at which patent applications grow from 2004 until 2014 differ largely between Chinese universities: universities that are new to patenting strongly increase their patenting activity (e.g. Xinjiang University has an average annual growth rate of $176 \%$ per year), while universities with established patenting activity, like Tsinghua University, have lower growth rates (14\% in the case of Tsinghua University).

\subsection{Whole network analysis}

\subsubsection{Increased network efficiency}

Before 2008, the diameter and effective diameter of each year's network remain stable (around 4). However, because of the network's explosive growth in 2009, the diameters increase significantly; reaching over 8 in 2009 (Fig. 4). Afterwards, in contrast to the 


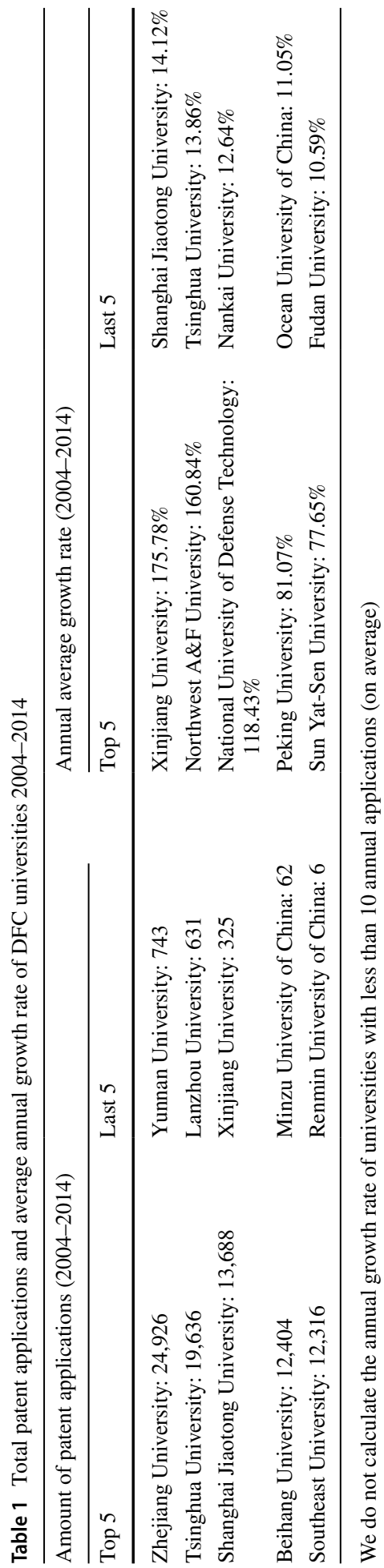




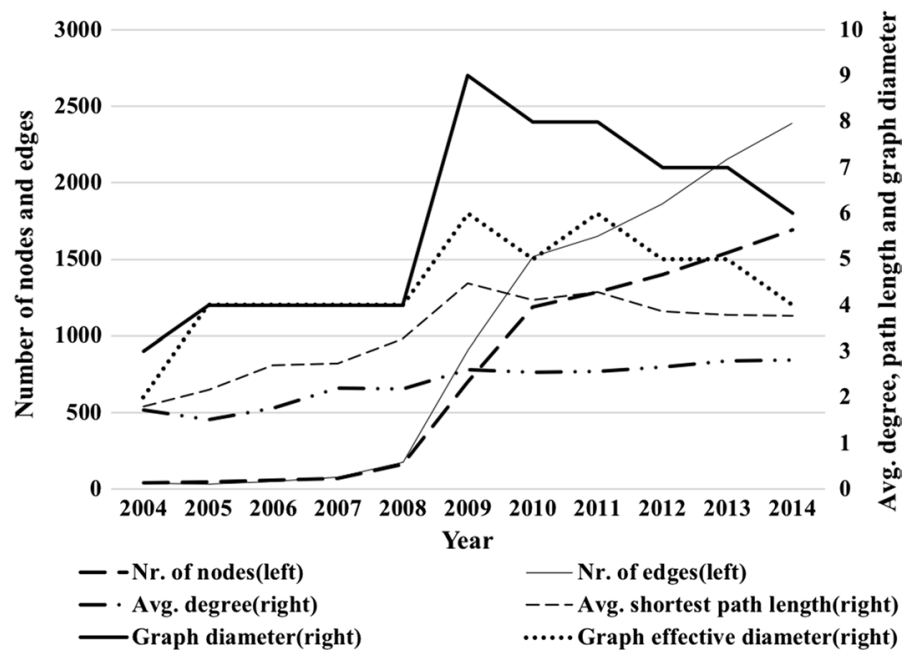

Fig. 4 Evolution of classic network indexes (Source: own set-up)

$$
0,2
$$

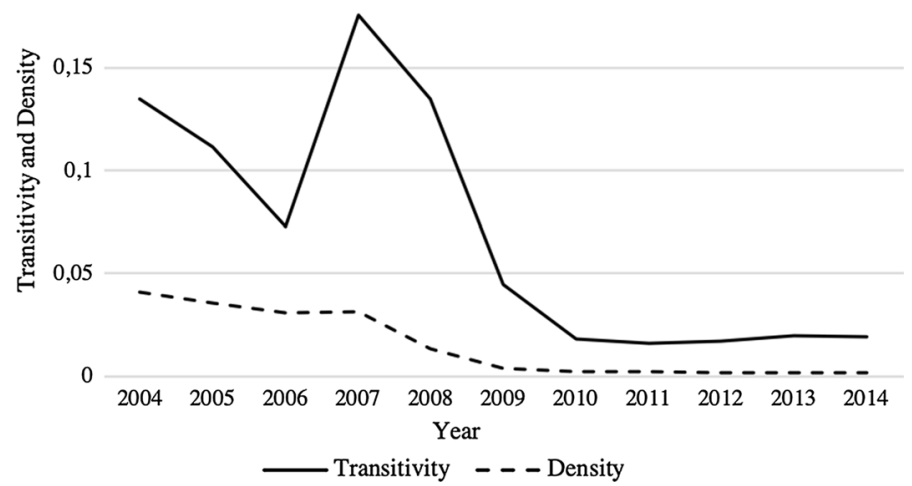

Fig. 5 Network transitivity and density (Source: own set-up)

conventional wisdom that the diameter should increase as a function of the number of nodes, i.e., $O(\log n)$ or $O(\log (\log n))$ (Leskovec et al. 2005), the diameters of the Chinese university knowledge transfer networks shrink continuously, which indicates that the distances between nodes in the networks decrease as the networks grow. This means that the average shortest path to transfer knowledge decreases over time (Fig. 4) and points to the existence of or evolution towards a more efficient university knowledge transfer network. Leskovec et al. (2005) conclude that a shrinking diameter is a robust and intrinsic phenomenon in real-world networks (Leskovec et al. 2005). A decrease in distance between pairs of universities is the result of new universities joining the network and new ties emerging in the network, acting as bridges between the universities. 


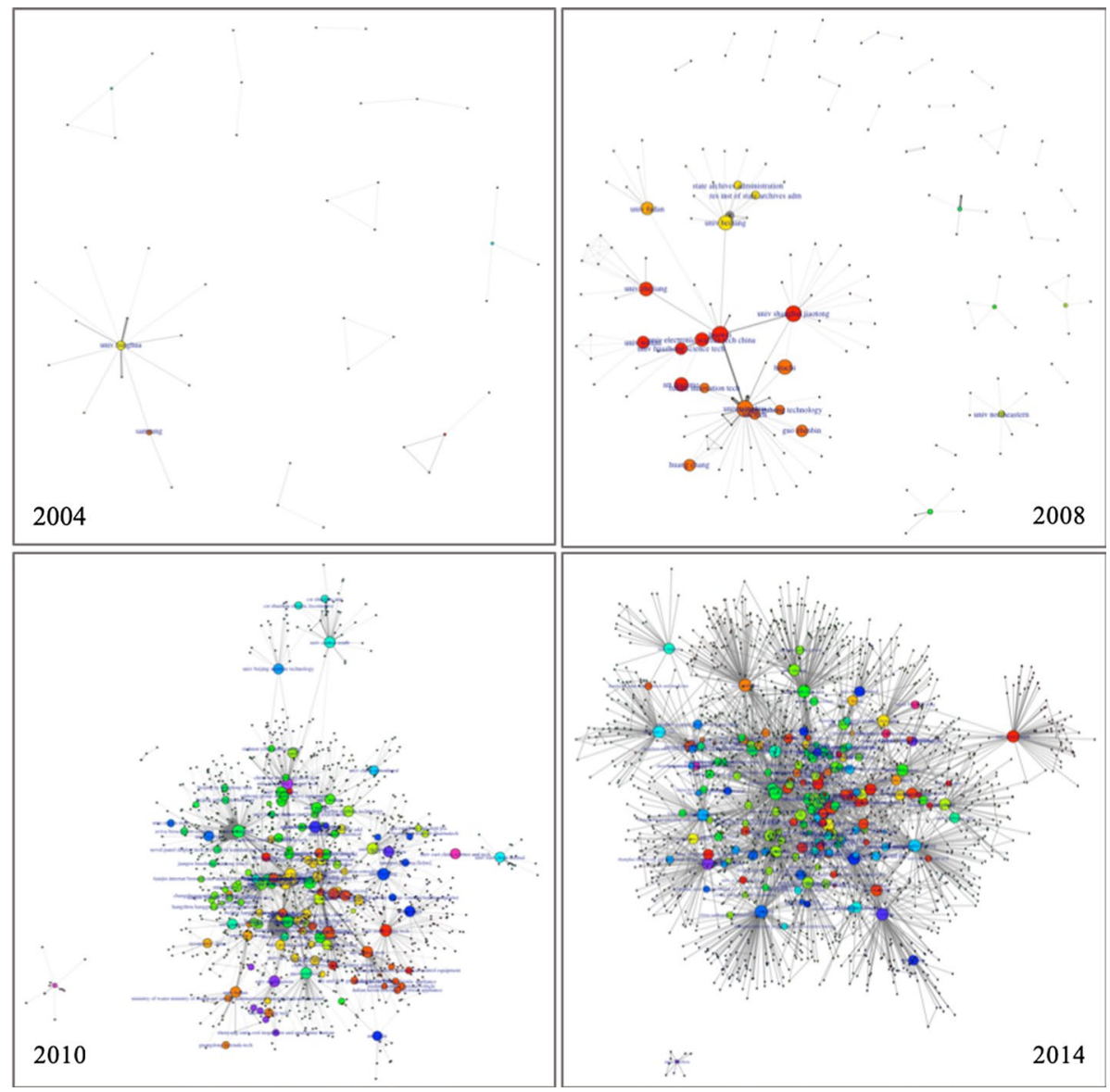

Fig. 6 Chinese universities' knowledge transfer networks (Source: own set-up)

\subsubsection{Three evolutionary stages}

Drawing upon the network's transitivity and density measures over time (Fig. 5) and a visualization of the network dynamics (Fig. 6) allows us to distinguish three evolutionary stages of the Chinese university knowledge transfer network. The network is in an early stage and remains single centered until 2008 with Tsinghua University at its center. From 2008 to 2010, the knowledge transfer network enters an expansion stage: network transitivity and density measures drop rapidly as the network increases in complexity and becomes multi-centered around key nodes. From 2011 onwards, the network's complexity stabilizes, indicating that it enters a mature stage.

\subsubsection{A power-law pattern}

After the explosive growth in 2009 , we observe that the number of ties grows faster than the number of nodes in the network. Meanwhile, the transitivity and density measures 
Table 2 Community number and size of Chinese university knowledge transfer networks

\begin{tabular}{lllll}
\hline Year & $\begin{array}{l}\text { No. of com- } \\
\text { munities }\end{array}$ & Max. size & Min. size & Ave. size \\
\hline 2004 & 10 & 14 & 2 & 4 \\
2005 & 15 & 12 & 1 & 3 \\
2006 & 13 & 16 & 2 & 4 \\
2007 & 12 & 17 & 2 & 6 \\
2008 & 29 & 31 & 2 & 6 \\
2009 & 32 & 85 & 1 & 22 \\
2010 & 32 & 126 & 1 & 37 \\
2011 & 47 & 140 & 1 & 27 \\
2012 & 38 & 160 & 1 & 37 \\
2013 & 41 & 178 & 1 & 38 \\
2014 & 47 & 211 & 1 & 36 \\
\hline
\end{tabular}

The $p$ values of the Wilcoxon rank-sum test in each year's communities are much smaller than 0.001, which indicates that the detected communities in each year's network are significant. In each year's communities, we do not test the smallest $20 \%$ communities because generally these communities only contain between one and three organizations

drop fast between 2008 and 2010 and stagnate afterwards due of the rise in the number of nodes from 2008 to 2010 . This phenomenon goes against conventional wisdom, which would expect the number of ties to grow linear with the number of nodes and have a constant average degree (Leskovec et al. 2005). We analyze the relation between the number of nodes $\mathrm{N}(\mathrm{t})$ and the number of ties $\mathrm{E}(\mathrm{t})$ by estimating $E(t) \propto N(t)^{a}, E(t) \propto N(t), E(t) \propto e^{N(t)}$, $E(t) \propto \ln N(t)$, etc. We find that the evolution of the Chinese university knowledge transfer network follows a power-law pattern since the regression $E(t) \propto N(t)^{1.125}$ renders the highest value for $\mathrm{R}^{2}(0.998)$ and the densification exponent (1.125) lays between the values one and two. This confirms that the number of ties grows faster than the number of nodes over the years and that universities get easier access to knowledge and other knowledge bases. And while a decrease of the density index over time would argue for lower efficiency and access to new knowledge, this argument is countered by the density of large-scale networks outweighing the density of small-scale networks.

\subsection{Community level analysis}

Along with the increased complexity of the Chinese university knowledge transfer network, the number of network communities grew fast over the past decade: from 10 communities in 2004 to 47 in 2014 (Table 2). Interestingly, the maximum size of communities grows much faster than the number of communities. The largest community in 2008 consists of 31 organizations, while in 2014, the largest community contains more than 200 organizations. In contrast, the average size of a community stabilized around 35-40 from 2012 onwards.

Table 2 also shows a significant trend of skewed distribution. Each year, most communities are of small or medium size. However, there are several large communities in each year's network that have significantly larger sizes than other communities in the respective 
Table 3 Regression coefficients and $\mathrm{R}^{2}$ of $\log$ (count) and $\log$ (degree), 2008-2014

\begin{tabular}{llllllll}
\hline Year & 2008 & 2009 & 2010 & 2011 & 2012 & 2013 & 2014 \\
\hline $\begin{array}{l}\text { Regression coeffi- } \\
\text { cients Log(count) }\end{array}$ & -0.542 & -0.604 & -0.583 & -0.582 & -0.606 & -0.611 & -0.614 \\
$\begin{array}{l}\text { Log(degree) } \\
\mathrm{R}^{2}\end{array}$ & 0.790 & 0.773 & 0.637 & 0.627 & 0.663 & 0.659 & 0.667
\end{tabular}

In the years prior to 2008, the degrees of nodes have less than ten observations in the regressions, which makes it inappropriate to calculate the regression coefficients

year. Moreover, the size gap between the average size of communities and the larger ones continues to increase over time. This means that along with the growth of the Chinese university knowledge transfer network, an aggregation phenomenon appears in the communities' evolution. Oligopolistic communities emerge and rule the network. Typically, knowledge within communities is more easily accessible to its members and communities exert control over stocks of knowledge. The number of oligopolistic communities is relatively stable over time; less than 5 in each year.

\subsection{Node level analysis}

\subsubsection{Key universities take on central positions within the network}

Based on degree measures, we identify important universities in the Chinese university knowledge transfer network and track the evolution of these universities' positions over time. We calculate the degree of each university in each year's network. Nodes with larger degrees are identified as key nodes. In each year's network the sum of the degrees of key nodes represents $20 \%$ of the total degree of all the nodes.

As the network increases in complexity, key universities among the 42 DFC universities largely remain the same over the years (e.g., Tsinghua University and Zhejiang University), which indicates a stable growth of the knowledge transfer network of Chinese universities. However, this also hints that it might be difficult for other DFC universities to become key nodes. The six most stable key universities are situated in the most important Chinese economic areas (Beijing, the Yangtze River Economic Circle, and the Pearl River Economic Circle). Some companies, such as Huawei in 2008 and State Grid in 2013, are temporary key nodes in the university knowledge transfer network.

We find the degree distribution of the university knowledge transfer heavy-tailed with many low degree nodes and few high degree nodes in the network. To measure the distribution's skewness over time, we run the a $\log ($ count $) \propto \log$ (degree) regression with the degrees (degree) of all the nodes in all the networks from 2004 to 2014 and their occurrences (count). The regression coefficient reflects the degree distribution. For 2004-2014, we get a regression coefficient of- $-(0.602)$ and a high $\mathrm{R}^{2}$ of 0.829 , which confirms that we have few nodes with a high degree and a majority of nodes with a low degree.

We find that the absolute values of the regression coefficients increase over time (Table 3), which indicates that the degree distribution becomes increasingly skewed. According to Newman (2001), an absolute value of the coefficient of 2 forms a cut-off between two fundamentally different behaviors of networks. With an absolute value less than 2, the properties of the network are dominated by few organizations that have a large number of partners, whereas 

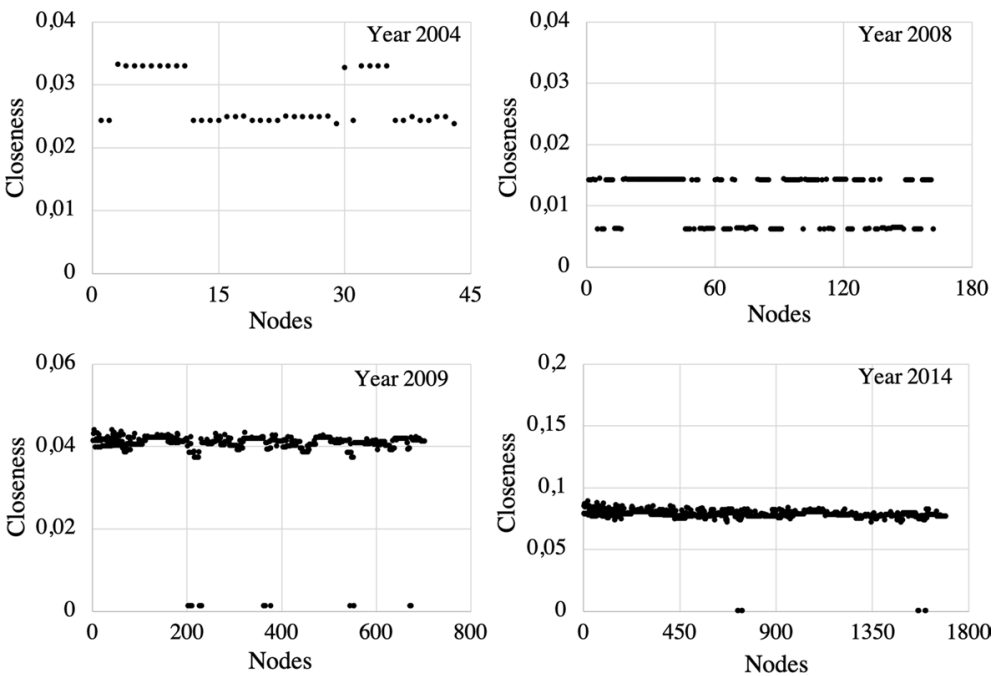

Fig. 7 Distribution of Chinese universities' closeness 2004-2014 (Source: own set-up)

networks with an absolute value larger than 2 are dominated by those nodes with a few partners. We find ourselves in the former case and confirm that, as our network grows, some key universities with considerably large amounts of neighbors take on central positions and influence network properties; i.e. they increase their ease of access to knowledge. This trend gets confirmed by the distributions of closeness and betweenness measures which become increasingly skewed over time.

\subsubsection{Universities' knowledge access and control}

The distribution of Chinese universities' closeness hits a crucial point in 2009 (Fig. 7). Before 2009, closeness distributions show no particular outliers that have significantly smaller closeness values. After 2009, several nodes have significantly smaller closeness values than the majority of the nodes. This translates to several universities occupying a more central position within the Chinese university knowledge transfer networks. Such positioning allows those universities to have an easier access to knowledge from the network.

From 2004 onwards and especially in the years prior to 2009, the betweenness distributions are obviously skewed; only several nodes have significantly higher betweenness values, while most of the nodes have very low values (Fig. 8). This means that in early networks, several key players control the network's knowledge flows which renders the efficiency of knowledge transfer relatively low. However, as the complexity of the network and knowledge flows grow rapidly since 2009 , the number of nodes that have relatively high betweenness values increase. More universities play the role of knowledge transfer vehicles in the network and share control over the knowledge flows.

\subsection{Inter-regional university knowledge transfer analysis}

We find that the amount of inter-regional knowledge transfer activity is scarce when compared to intra-regional knowledge transfer activity. However, our findings show that 

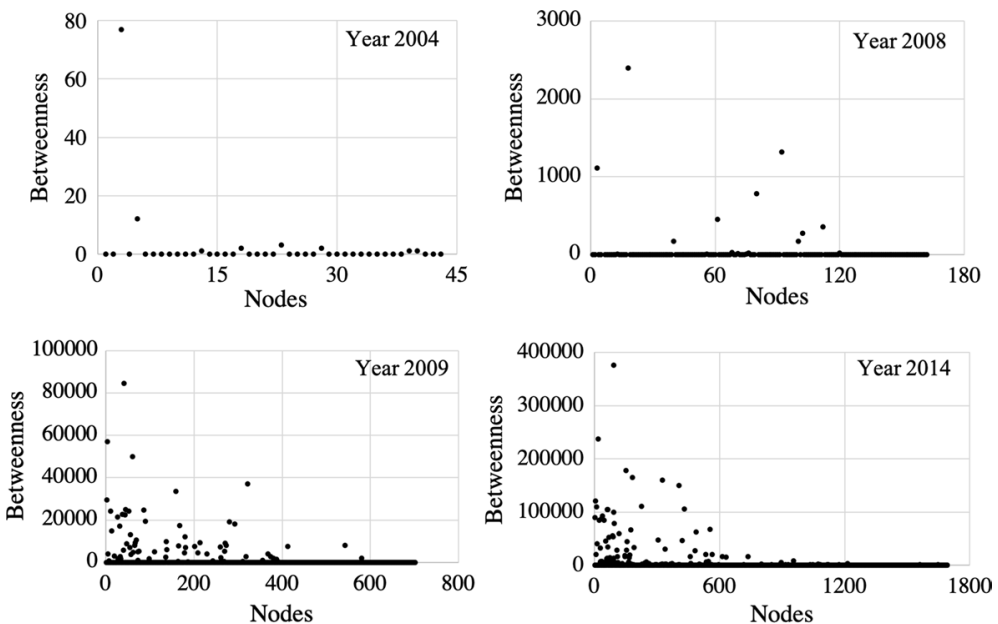

Fig. 8 Distribution of Chinese universities' betweenness 2004-2014 (Source: own set-up)

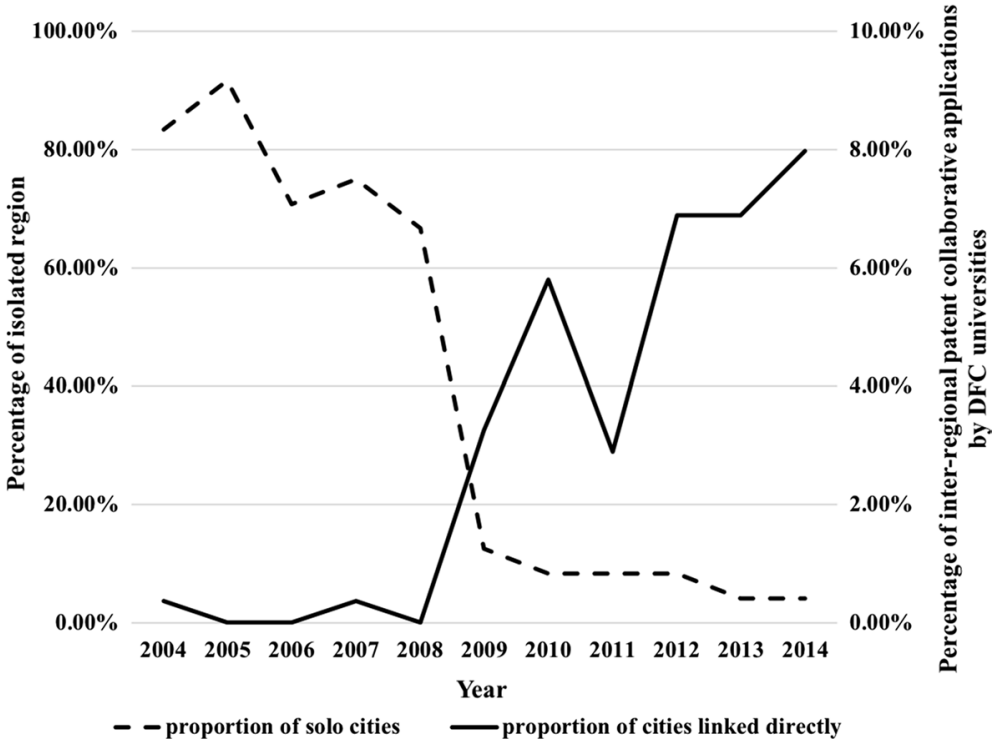

Fig. 9 Increase in cross-regional knowledge transfer collaborations and decrease in isolated regions of knowledge transfer (Source: own set-up)

inter-regional university knowledge transfer is increasing steadily (Fig. 9). In 2014, the percentage of inter-regional joint patent applications by DFC universities reaches $8.00 \%$, while in 2004 , the percentage is lower than $1 \%$. Meanwhile, the percentage of isolated Chinese regions in the university knowledge transfer network decreases from 
around 90\% to less than 5\% with a steep drop in 2009 (Fig. 9). DFC universities increasingly establish inter-regional knowledge transfer collaborations.

\section{Discussion}

\subsection{Policy and knowledge transfer network evolution}

Throughout the evolution of the Chinese university knowledge transfer network, 2008 acts as a pivotal year. The year 2008 is a milestone in China's innovation strategy with the announcement of many profound policies including the implementation of China's IP strategy to enhance IP creation, application, protection and management and the revision of the Chinese patent law to strengthen the protection of IP rights and to encourage and promote technological innovation (Chen et al. 2016). Such innovation policies highly promote autonomous innovation and encourage patent applications. Lerner (2009), for example, analyzing 60 countries, confirms that both domestic and foreign patent applications increase in countries that ensure stronger IP protections. In particular for China, Liang and Xue (2010) note that the revision of Chinese patent law inspired rapid growth in patent applications (Liang and Xue 2010). Next to the innovation policies, China countered the turbulence of the 2008's financial crisis with an anticyclical policy and strong stimulus plan to minimize the impact of the global financial crisis. The state council of China launched the Chinese economic stimulus plan in November 2008, which sought to inject 4 trillion RMB (586 billion dollar) into the economy before the end of 2010. The plan focused on infrastructure and technological advancements. Such stimulus goes hand in hand with the explosive growth of patenting activity in the period of 2008-2010. It is clear that these consecutive policy plans impacted the growth of Chinese university patents and shaped the evolution of the Chinese university knowledge transfer network towards its three distinct stages over time. Thereby, this paper differs from existing network evolution literature where evolutionary stages are less pronounced (e.g. Xu et al. 2019; Breznitz et al. 2018; De Noni et al. 2018; Cantner and Rake 2014; Giuliani 2013). Such impact reminds us on how a political and legal framework is key to foster knowledge creation and diffusion within a country and provide a larger amount of universities and organizations with the opportunity to access new knowledge through knowledge transfer collaborations.

\subsection{Policy and inter-regional knowledge transfer}

Such policy support should now be devoted towards stimulating inter-regional knowledge transfer. Previous research has shown that inter-regional knowledge transfer activities in China are scarce when compared to intra-regional knowledge transfer (Gao et al. 2011; Hong 2008). Our study confirms this finding, but we note that inter-regional knowledge transfer activity is increasing steadily. In Europe, such inter-regional networks are crucial for the development of national innovation systems (Hoekman et al. 2009) and leverage knowledge transfer towards isolated organizations and lagging-behind European regions (De Noni et al. 2018). Thus, further encouragement by local and national government is needed on an inter-regional level to overcome the underdevelopment of some Chinese regions. For example, in a German context, Mitze and Strotebeck (2019) show that the stimulus of network and cluster policies, mainly collaborative R\&D funding, positively affect inter-regional collaborations. Governments could cultivate regional interpersonal 
networks by encouraging inter-regional mobility and subsidizing joint research and development projects or joint regional conferences (Gao et al. 2011). Similar effort, although in a cross-country setting, is found in Europe with the introduction of the 'European Research Area' in 2000 (Maurseth and Verspagen 2002). Overall, such efforts allow less favored regions to extend their knowledge base and subsequently attract new knowledge collaborations (De Noni et al. 2018). We particularly encourage Chinese governments to stimulate collaboration amongst the $42 \mathrm{DFC}$ universities and their inter-organizational networks. These collaborations are surprisingly limited but are crucial conduits for knowledge transfer between regions (Giuliani 2013).

\subsection{The university role within knowledge transfer networks}

Our study confirms the Chinese decentralization trend, indicated by previous scholars (e.g. Hong 2008), from a university perspective and with more recent data. Our findings on the aggregation phenomenon and the emergence of oligopolistic communities with key nodes taking central positions over time are in line with similar, yet also scarce, studies using a Western empirical setting. Consistent with the findings of Yang et al. (2019), our Chinese university knowledge transfer network can be characterized by a small-world phenomenon as all nodes in the network are close to almost all other nodes through a small number of interconnecting ties, despite the fast expansion of the network (Watts and Strogatz 1998). Similar results have been reported in a Japanese (Kajikawa et al. 2010) and Western context (Balconi et al. 2004). In this network, universities take central positions; they can access knowledge from other organizations with less effort and can exert a certain control over the knowledge flows (Kajikawa et al. 2010). Maggioni and Uberti (2009), studying network properties of five European countries find a similar domination through a regional perspective, where few central nodes take control over the knowledge in the network, leaving some regions marginalized. Fleming and Frenken (2007), find a dramatic aggregation phenomenon of the regional inventor network in Silicon Valley around 1989 in which isolated networks form one giant network.

Our findings trigger universities to better understand the embedded position of a university within a region and its relations towards other universities, industries, and regions with respect to knowledge transfer as such embeddedness brings along strategic implications (Xu et al. 2019). For example, universities embedded within less favored regions ought to strengthen their knowledge base through accessing new knowledge, in particular through new knowledge transfer collaborations with universities and organizations with strong knowledge bases. However, universities embedded within those favored regions, having a strong intra-regional knowledge transfer network and community, may exert certain control over knowledge within the community and knowledge flows across communities, for example due to competition for resources on a national level or the propensity to network among themselves on a regional level (De Noni et al. 2018). So, while more universities have become key players within the Chinese knowledge transfer network and leverage access to knowledge, these represent some hurdles to overcome if universities are to increase their role as knowledge bridges in inter-regional knowledge transfer. 


\section{Conclusion and future research}

\subsection{Conclusion}

To further explore how universities access knowledge through networks over time, this paper draws upon resource dependency theory and inter-organizational networks. We collect patent data of 42 DFC universities and study the structural properties of the Chinese university knowledge transfer network over time. We conduct a whole network level, community level, and the node level analysis and explore the universities' inter-regional knowledge transfer activities. Our results point to the existence of a remarkably highly efficient university knowledge transfer network. Despite an increased complexity, the network brings forth increased knowledge transfer and connectivity amongst its members. New universities join the network and new ties emerge in the network, acting as knowledge bridges between universities already present in the network. The network moves from an early-stage single-centered network to a mature multi-centered network through a powerlaw pattern. Such movement allows for an aggregation phenomenon to appear as oligopolistic communities emerge and rule the network. While knowledge is more easily shared and accessible within communities, their existence also brings along certain control over knowledge bases embedded in those communities. Indeed, at the node level, we notice key universities dominating the network and taking on central positions within the network, even after expansion of the network, which allows them to gain control and easier access to knowledge from the network. It also hints that it might be difficult for other DFC universities to become key nodes in the network. The role of those universities acting as knowledge transfer bridges in the network becomes crucial. On an inter-regional level, our findings point to steadily increasing knowledge transfer activity, which is key in overcoming the underdevelopment of some Chinese regions. Overall, next to the trend of increased patenting activity, we observe a strong growth in the patenting activity of less-experienced Chinese universities.

Our study contributes to the literature in several ways. First, little studies capture how inter-organizational knowledge transfer networks evolve over time, i.e. knowledge transfer network dynamics. Also, while universities have emerged as key actors to transfer knowledge, few studies actually focus on the role and perspective of universities within knowledge transfer networks. However, this is crucial to learn how universities construct and maintain knowledge collaborations with other organizations. Second, existing studies ignore the theoretical link between patent data, social networks and knowledge transfer. We draw upon the resource dependency theory to understand co-patenting collaborations and use social networks to analyze the university knowledge transfer networks. Third, and in particular addressing the Chinese context, few studies investigate knowledge transfer networks on a country level. Existing studies mainly focus on a block-level methodology or on patent licensing and citation data sets. Also, Chinese inter-regional knowledge transfer deserves increased attention since it is key to overcome the socio-economic underdevelopment of some regions.

\subsection{Limitations and future research}

While researchers have made considerable progress in analyzing organizations' knowledge transfer networks, only few of them delved deeper into the collaborative behavior of 
organizations, while it is the origin of community and network emergence and evolution. Analyzing such behavior allows us to understand how new ties emerge within a network and how long these ties survive to explain the formation and evolution of knowledge transfer networks. This paper provides a solid foundation for future work by uncovering the evolution of Chinese universities' knowledge transfer networks, the dynamics of network structure measures, and organizational positions. Moreover, the rapid growth of such networks and the clear three stages provide a unique context to study the emergence and evolution of inter-organizational collaboration ties. Future research might test how and which factors influence organizations' collaborative behavior in the context of Chinese universities' knowledge transfer networks, especially looking to the influence of previous collaboration, organization characteristics, and of common partners in setting up new collaborations. Future research might also address sectoral distances which have been found to play a relevant role in knowledge flows between similar regions (Maggioni and Uberti 2009). Based on such research, mechanisms of organizational behavior, new ties and networks can be predicted.

Our paper only takes into account joint patent applications, which is not the sole mechanism for knowledge transfer. Focusing on patent data in isolation may misrepresent the nature of universities' effect on the innovation ecosystem, and a more comprehensive study should include a focus on the channels through which universities transfer their knowledge (Agrawal and Henderson 2002). As a patent can either be the precursor or the result of knowledge transfer, there is a lag between the moment of patent application and the moment when knowledge transfer actually happens. We do not capture this lag with our current approach. Moreover, our data is limited in the sense that we only take into account those patents where a DFC university is involved. A more comprehensive study might take into account all Chinese universities' knowledge transfer networks to consider the impact of the 42 DFC universities, compared to other universities and firms.

Whereas our study focuses on describing the evolution of the university knowledge transfer network, we do not take into account any measures of universities' innovation performance nor do we check the bidirectional correlation or causation between a university's innovation performance and its position in the network. This is an interesting path for further research since we find that several powerful universities occupy central positions in the Chinese universities' knowledge transfer networks over time. The literature has shown that organizations enjoy better innovation performance if they occupy central network positions that provide access to new knowledge developed by other organizations (Tsai 2001). Next, we did not capture the conceptual distinction between voluntary and involuntary or intended and unintended collaborations within networks (Oliver 1990; Zaheer et al. 2010). For example, knowledge collaborations may intentionally be exploited as a response to dependencies amongst organizations to enhance one's power or control. Such studies, diving into political power theories (e.g. Zald), could increase our understanding on how inter-organizational ties foster or impede the use of power and vice versa (Oliver 1990). In terms of geographical interest, our study addresses the imbalance of studies being predominantly based on western countries and universities (Cunningham and O'Reilly 2018; Perkmann et al. 2013; Wang et al. 2015a). While we discuss and contrast our findings with Western literature, additional efforts are needed to integrate findings from both literature streams and deduct best practices.

Funding This study is funded by the China Scholarship Council. 


\section{Compliance with ethical standards}

Conflict of interest The authors declare that they have no conflict of interest.

Open Access This article is distributed under the terms of the Creative Commons Attribution 4.0 International License (http://creativecommons.org/licenses/by/4.0/), which permits unrestricted use, distribution, and reproduction in any medium, provided you give appropriate credit to the original author(s) and the source, provide a link to the Creative Commons license, and indicate if changes were made.

\section{Appendix A: Definitions and calculation measures of key concepts and variables}

\begin{tabular}{|c|c|}
\hline Concept/variable & Definition \\
\hline Node & $\begin{array}{l}\text { Actors in the network, in this paper, nodes are organizations such as } \\
\text { universities, companies, etc }\end{array}$ \\
\hline Tie & $\begin{array}{l}\text { Ties between two nodes, in this paper, one tie between two organiza- } \\
\text { tions represents one joint patent application between them }\end{array}$ \\
\hline Transitivity & $\begin{array}{l}\text { Also called clustering coefficient, is a measure of the extent to which } \\
\text { nodes tend to cluster together in the network }\end{array}$ \\
\hline Density & $\begin{array}{l}\text { The ratio of the number of real ties and the maximum possible number } \\
\text { of ties in the network }\end{array}$ \\
\hline Shortest path length & The minimum number of steps needed to reach one node from another \\
\hline Average shortest path length & $\begin{array}{l}\text { The average number of steps along the shortest paths for all possible } \\
\text { pairs of nodes in the network }\end{array}$ \\
\hline Diameter & Shortest path length between the two most distant nodes in the network \\
\hline 90th percentile effective diameter & The number of ties needed on average to reach $90 \%$ of all other nodes \\
\hline Community & $\begin{array}{l}\text { A subnetwork containing nodes which are more densely tied to each } \\
\text { other than to the rest of the network }\end{array}$ \\
\hline Degree & The number of ties a node has \\
\hline Normalized degree & Degree divided by $(\mathrm{N}-1)$ \\
\hline Closeness & $\begin{array}{l}\text { The sum of the length of the shortest paths between the node and all } \\
\text { other nodes in the network }\end{array}$ \\
\hline Normalized closeness & Closeness divided by $(\mathrm{N}-1)$ \\
\hline Betweenness & $\begin{array}{l}\text { Calculates the node stays on how many shortest paths of other nodes } \\
\text { pairs }\end{array}$ \\
\hline Normalized betweenness & $\begin{array}{l}\text { Betweenness divided by the number of possible ties in the network, } \\
\text { which is } 0.5 \times(\mathrm{N}-1) \times(\mathrm{N}-2)\end{array}$ \\
\hline
\end{tabular}

Source: igraph R manual pages (https://igraph.org/r/doc/)

\section{References}

Agrawal, A. (2001). University-to-industry knowledge transfer: Literature review and unanswered questions. International Journal of Management Reviews. https://doi.org/10.1111/1468-2370.00069.

Agrawal, A., \& Henderson, R. (2002). Putting patents in context: From exploring MIT knowledge transfer. Management Science. https://doi.org/10.1287/mnsc.48.1.44.14279.

Ahuja, G., Soda, G., \& Zaheer, A. (2012). The genesis and dynamics of organizational networks. Organization Science. https://doi.org/10.1287/orsc.1110.0695. 
AlAzzawi, S. (2011). Multinational corporations and knowledge flows: Evidence from patent citations. Economic Development and Cultural Change, 59(3), 649-680.

Balconi, M., Breschi, S., \& Lissoni, F. (2004). Networks of inventors and the role of academia: An exploration of Italian patent data. Research Policy, 33, 127-145.

Battistella, C., De Toni, A. F., \& Pillon, R. (2016). Inter-organisational technology/knowledge transfer: A framework from critical literature review. The Journal of Technology Transfer, 41(5), 1195-1234.

Bavelas, A. (1950). Communication patterns in task-oriented groups. The Journal of the Acoustical Society of America. https://doi.org/10.1121/1.1906679.

Bedi, P., \& Sharma, C. (2016). Community detection in social networks. Wiley Interdisciplinary Reviews: Data Mining and Knowledge Discovery. https://doi.org/10.1002/widm.1178.

Belderbos, R., Cassiman, B., Faems, D., Leten, B., \& Van Looy, B. (2014). Co-ownership of intellectual property: Exploring the value-appropriation and value-creation implications of co-patenting with different partners. Research Policy. https://doi.org/10.1016/j.respol.2013.08.013.

Borgatti, S. P., \& Foster, P. C. (2003). The network paradigm in organizational research: A review and typology. Journal of Management. https://doi.org/10.1016/s0149-2063(03)00087-4.

Breznitz, S. M., Clayton, P. A., Defazio, D., \& Isett, K. R. (2018). Have you been served? The impact of university entrepreneurial support on start-ups' network formation. The Journal of Technology Transfer, 43(2), 343-367.

Burt, R. S. (1992). Structural holes: The social structure of competition. Cambridge, MA: Harvard University Press.

Cantner, U., \& Rake, B. (2014). International research networks in pharmaceuticals: Structure and dynamics. Research Policy, 43(2), 333-348.

Chen, A., Patton, D., \& Kenney, M. (2016). University technology transfer in China: A literature review and taxonomy. Journal of Technology Transfer. https://doi.org/10.1007/s10961-016-9487-2.

Choe, H., \& Lee, D. H. (2017). The structure and change of the research collaboration network in Korea (2000-2011): Network analysis of joint patents. Scientometrics, 111(2), 917-939.

Csardi, G., \& Nepusz, T. (2006). The igraph software package for complex network research. InterJournal, Complex Systems, 1695(5), 1-9.

Cunningham, J. A., \& O'Reilly, P. (2018). Macro, meso and micro perspectives of technology transfer. Journal of Technology Transfer, 43(3), 545-557. https://doi.org/10.1007/s10961-018-9658-4.

De Moortel, K., \& Crispeels, T. (2018). International university-university technology transfer: Strategic management framework. Technological Forecasting and Social Change, 135, 145-155. https://doi. org/10.1016/j.techfore.2018.05.002.

De Noni, I., Orsi, L., \& Belussi, F. (2018). The role of collaborative networks in supporting the innovation performances of lagging-behind European regions. Research Policy, 47(1), 1-13.

De Prato, G., \& Nepelski, D. (2012). Global technological collaboration network: Network analysis of international co-inventions. Journal of Technology Transfer. https://doi.org/10.1007/s1096 1-012-9285-4.

Fernández-Olmos, M., \& Ramírez-Alesón, M. (2017). How internal and external factors influence the dynamics of SME technology collaboration networks over time. Technovation, 64, 16-27.

Fisch, C. O., Block, J. H., \& Sandner, P. G. (2016). Chinese university patents: Quantity, quality, and the role of subsidy programs. Journal of Technology Transfer. https://doi.org/10.1007/s10961-014-9383-6.

Fisch, C. O., Hassel, T. M., Sandner, P. G., \& Block, J. H. (2015). University patenting: A comparison of 300 leading universities worldwide. Journal of Technology Transfer. https://doi.org/10.1007/s1096 1-014-9355-x.

Fleming, L., \& Frenken, K. (2007). The evolution of inventor networks in the Silicon Valley and Boston regions. Advances in Complex Systems, 10(01), 53-71. https://doi.org/10.1142/s0219525907000921.

Fong, P. S. W., Chang, X., \& Chen, Q. (2018). Faculty patent assignment in the Chinese mainland: Evidence from the top 35 patent application universities. Journal of Technology Transfer. https://doi. org/10.1007/s10961-015-9434-7.

Freeman, L. C. (1977). A set of measures of centrality based on betweenness. Sociometry. https://doi. org/10.2307/3033543.

Freeman, L. C. (1978). Centrality in social networks conceptual clarification. Social Networks. https:// doi.org/10.1016/0378-8733(78)90021-7.

Gao, X., Guan, J., \& Rousseau, R. (2011). Mapping collaborative knowledge production in China using patent co-inventorships. Scientometrics. https://doi.org/10.1007/s11192-011-0404-z.

Giuliani, E. (2013). Network dynamics in regional clusters: Evidence from Chile. Research Policy, 42(8), 1406-1419.

Guan, J., Zhang, J., \& Yan, Y. (2015). The impact of multilevel networks on innovation. Research Policy, 44(3), 545-559. 
Gulati, R., \& Gargiulo, M. (1999). Where do interorganizational networks come from? American Journal of Sociology. https://doi.org/10.1086/210179.

Henderson, J. V. (2007). Understanding knowledge spillovers. Regional Science and Urban Economics, 37(4), 497-508.

Henderson, R., Jaffe, A. B., \& Trajtenberg, M. (1998). Universities as a source of commercial technology: A detailed analysis of university Patenting, 1965-1988. Review of Economics and Statistics. https://doi.org/10.1162/003465398557221.

Hoekman, J., Frenken, K., \& van Oort, F. (2009). The geography of collaborative knowledge production in Europe. Annals of Regional Science, 43, 721-738.

Hong, W. (2008). Decline of the center: The decentralizing process of knowledge transfer of Chinese universities from 1985 to 2004. Research Policy. https://doi.org/10.1016/j.respol.2007.12.008.

Huggins, R., Prokop, D., \& Thompson, P. (2019). Universities and open innovation: The determinants of network centrality. The Journal of Technology Transfer. https://doi.org/10.1007/s10961-019-09720-5.

Jiang, J., Goel, R. K., \& Zhang, X. (2017). Knowledge flows from business method software patents: Influence of firms' global social networks. The Journal of Technology Transfer, 44, 1-27.

Kajikawa, Y., Takeda, Y., Sakata, I., \& Matsushima, K. (2010). Multiscale analysis of interfirm networks in regional clusters. Technovation, 30(3), 168-180.

Kroll, H., \& Liefner, I. (2008). Spin-off enterprises as a means of technology commercialisation in a transforming economy-evidence from three universities in China. Technovation. https://doi.org/10.1016/j. technovation.2007.05.002.

Lerner, J. (2009). The empirical impact of intellectual property rights on innovation: Puzzles and clues. American Economic Review, 99(2), 343-348.

Leskovec, J., Kleinberg, J., \& Faloutsos, C. (2005). Graphs over time: Densification laws, shrinking diameters and possible explanations. In KDD. https://doi.org/10.1145/1081870.1081893.

Li, G.-C., Lai, R., D’Amour, A., Doolin, D. M., Sun, Y., Torvik, V. I., et al. (2014). Disambiguation and co-authorship networks of the US patent inventor database (1975-2010). Research Policy, 43(6), 941-955.

Li, J., Tan, Q. M., \& Bai, J. H. (2010). Spatial econometric analysis of regional innovation production in China: Based on the empirical research on static and dynamic spatial panel model. Management World, 7, 43-55.

Liang, L., \& Zhu, L. (2002). Major factors affecting China's inter-regional research collaboration: Regional scientific productivity and geographical proximity. Scientometrics, 55(2), 287-316. https://doi. org/10.1023/A:1019623925759.

Liang, Z., \& Xue, L. (2010). The evolution of China's IPR system and its impact on the patenting behaviours and strategies of multinationals in China. International Journal of Technology Management, 51(2-4), 469-496.

Liu, F., \& Sun, Y. (2009). A comparison of the spatial distribution of innovative activities in China and the US. Technological Forecasting and Social Change, 76(6), 797-805.

Liu, X., \& White, S. (2001). Comparing innovation systems: A framework and application to China's transitional context. Research Policy. https://doi.org/10.1016/s0048-7333(00)00132-3.

Luan, C., Zhou, C., \& Liu, A. (2010). Patent strategy in Chinese universities: A comparative perspective. Scientometrics. https://doi.org/10.1007/s11192-010-0194-8.

Maggioni, M. A., \& Uberti, T. E. (2009). Knowledge networks across Europe: Which distance matters? Annals of Regional Science, 43, 691-720. https://doi.org/10.1007/s00168-008-0254-7.

Maurseth, P. B., \& Verspagen, B. (2002). Knowledge spillovers in Europe: A patent citations analysis. Scandinavian Journal of Economics, 104(4), 531-545. https://doi.org/10.1111/1467-9442.00300.

Mayhew, B. H. (1980). Structuralism versus individualism: Part 1, shadowboxing in the dark. Social Forces, 59(2), 335-375.

Meyer-Krahmer, F., \& Schmoch, U. (1998). Science-based technologies: University-industry interactions in four fields. Research Policy. https://doi.org/10.1016/s0048-7333(98)00094-8.

Mitze, T., \& Strotebeck, F. (2019). Determining factors of interregional research collaboration in Germany's biotech network: Capacity, proximity, policy? Technovation, 80, 40-53.

Molas-Gallart, J., \& Sinclair, T. (1999). From technology generation to technology transfer: The concept and reality of the 'Dual-Use Technology Centres'. Technovation. https://doi.org/10.1016/s0166 -4972(99)00063-2.

Morescalchi, A., Pammolli, F., Penner, O., Petersen, A. M., \& Riccaboni, M. (2015). The evolution of networks of innovators within and across borders: Evidence from patent data. Research Policy, 44(3), 651-668.

Motohashi, K., \& Yun, X. (2007). China's innovation system reform and growing industry and science linkages. Research Policy. https://doi.org/10.1016/j.respol.2007.02.023. 
Nahapiet, J., \& Ghoshal, S. (1998). Social capital, intellectual capital, and the organizational advantage. Academy of Management Review, 23(2), 242-266.

Newman, M. (2003). The structure and function of complex networks. SIAM Review. https://doi. org/10.1137/s003614450342480.

Newman, M. E. J. (2001). The structure of scientific collaboration networks. Proceedings of the National Academy of Sciences, 98(2), 404-409. https://doi.org/10.1073/pnas.98.2.404.

Newman, M. E. J., \& Girvan, M. (2004). Finding and evaluating community structure in networks. Physical Review E: Statistical, Nonlinear, and Soft Matter Physics. https://doi.org/10.1103/physreve.69.026113.

Noh, H., \& Lee, S. (2019). Where technology transfer research originated and where it is going: A quantitative analysis of literature published between 1980 and 2015. The Journal of Technology Transfer, 44(3), 700-740.

Oliver, C. (1990). Determinants of interorganizational relationships: Integration and future directions. The Academy of Management Review. https://doi.org/10.2307/258156.

Oliver, A. L., \& Ebers, M. (1998). Networking network studies: An analysis of conceptual configurations in the study of inter-organizational relationships. Organization studies, 19(4), 549-583.

Perkmann, M., Tartari, V., McKelvey, M., Autio, E., Broström, A., D’Este, P., et al. (2013). Academic engagement and commercialisation: A review of the literature on university-industry relations. Research Policy. https://doi.org/10.1016/j.respol.2012.09.007.

Pfeffer, J., \& Salancik, G. R. (1978). The external control of organizations: A resource dependence perspective. New York: Harper \& Row.

Phelps, C., Heidl, R., \& Wadhwa, A. (2012). Knowledge, networks, and knowledge networks: A review and research agenda. Journal of Management. https://doi.org/10.1177/0149206311432640.

Philpott, K., Dooley, L., O’Reilly, C., \& Lupton, G. (2011). The entrepreneurial university: Examining the underlying academic tensions. Technovation, 31(4), 161-170.

Pons, P., \& Latapy, M. (2005). Computing communities in large networks using random walks. In Proceedings of the 20th International Symposium on Computer and Information Sciences, volume 3733 of Lecture Notes in Computer Science (pp. 284-293). New York: Springer. https://doi. org/10.1007/11569596_31.

Powell, W. W., \& Grodal, S. (2005). Networks of innovators. In J. Fagerberg, D. C. Mowery, \& R. R. Nelson (Eds.), The Oxford handbook of innovation (p. 78). Oxford, UK: Oxford University Press.

Protogerou, A., Caloghirou, Y., \& Siokas, E. (2013). Twenty-five years of science-industry collaboration: The emergence and evolution of policy-driven research networks across Europe. The Journal of Technology Transfer, 38(6), 873-895.

Ribeiro, L. C., Kruss, G., Britto, G., Bernardes, A. T., \& da Motta e Albuquerque, E. (2014). A methodology for unveiling global innovation networks: Patent citations as clues to cross border knowledge flows. Scientometrics, 101(1), 61-83.

Romer, P. M. (1990). Endogenous technological change. Journal of Political Economy, 98(5, Part 2), S71-S102.

Scuotto, V., Del Giudice, M., \& Carayannis, E. G. (2017). The effect of social networking sites and absorptive capacity on SMES'innovation performance. The Journal of Technology Transfer, 42(2), 409-424.

Seck, A. (2012). International technology diffusion and economic growth: Explaining the spillover benefits to developing countries. Structural Change and Economic Dynamics, 23(4), 437-451.

Siegel, D. S., Waldman, D. A., Atwater, L. E., \& Link, A. N. (2003). Commercial knowledge transfers from universities to firms: Improving the effectiveness of university-industry collaboration. Journal of High Technology Management Research. https://doi.org/10.1016/s1047-8310(03)00007-5.

Singh, J. (2005). Collaborative networks as determinants of knowledge diffusion patterns. Management Science, 51(5), 756-770.

Soda, G., Usai, A., \& Zaheer, A. (2004). Network memory: The influence of past and current networks on performance. Academy of Management Journal, 47(6), 893-906.

Spithoven, A., Vlegels, J., \& Ysebaert, W. (2019). Commercializing academic research: A social network approach exploring the role of regions and distance. The Journal of Technology Transfer. https://doi.org/10.1007/s10961-019-09740-1.

Sun, Y. (2000). Spatial distribution of patents in China. Regional Studies, 34(5), 441-454. https://doi. org/10.1080/00343400050058693.

Thursby, J. G., Jensen, R., \& Thursby, M. C. (2001). Objectives, characteristics and outcomes of university licensing: A survey of major US universities. The Journal of Technology Transfer. https://doi. org/10.1023/a:1007884111883.

Tijssen, R. J. W. (2001). Global and domestic utilization of industrial relevant science: Patent citation analysis of science-technology interactions and knowledge flows. Research Policy, 30(1), 35-54. 
Töpfer, S., Cantner, U., \& Graf, H. (2017). Structural dynamics of innovation networks in German leading-edge clusters. The Journal of Technology Transfer. https://doi.org/10.1007/s10961-017-9642-4.

Tsai, W. (2001). Knowledge transfer in intraorganizational networks: Effects of network position. The Academy of Management Journal Academy of Management Journal. https://doi.org/10.2307/30694 43.

Wang, Y., Hu, D., Li, W., Li, Y., \& Li, Q. (2015a). Collaboration strategies and effects on university research: Evidence from Chinese universities. Scientometrics. https://doi.org/10.1007/s1119 2-015-1552-3.

Wang, Y., Pan, X., Ning, L., Li, J., \& Chen, J. (2015b). Technology exchange patterns in China: An analysis of regional data. The Journal of Technology Transfer, 40(2), 252-272.

Wang, Y., Wu, Y., Pan, Y., Ma, Z., \& Rousseau, R. (2005). Scientific collaboration in China as reflected in co-authorship. Scientometrics, 62(2), 183-198. https://doi.org/10.1007/s11192-005-0013-9.

Wasserman, S., \& Faust, K. (1994). Social network analysis: Methods and applications. American Ethnologist. https://doi.org/10.1525/ae.1997.24.1.219.

Watts, D. J., \& Strogatz, S. H. (1998). Collective dynamics of "small-world" networks. Nature, 393, $440-442$.

Wu, W. (2010). Managing and incentivizing research commercialization in Chinese universities. Journal of Technology Transfer. https://doi.org/10.1007/s10961-009-9116-4.

Xu, L., Li, J., \& Zhou, X. (2019). Exploring new knowledge through research collaboration: The moderation of the global and local cohesion of knowledge networks. The Journal of Technology Transfer, 44(3), 822-849.

Yang, W., Yu, X., Wang, D., Yang, J., \& Zhang, B. (2019). Spatio-temporal evolution of technology flows in China: Patent licensing networks 2000-2017. The Journal of Technology Transfer. https://doi. org/10.1007/s10961-019-09739-8.

Ye, X., Zhang, J., Liu, Y., \& Su, J. (2015). Study on the measurement of international knowledge flow based on the patent citation network. IJTM, 69(3/4), 229-245.

Zaheer, A., \& Bell, G. G. (2005). Benefiting from network position: Firm capabilities, structural holes, and performance. Strategic Management Journal, 26(9), 809-825.

Zaheer, A., Gözübüyük, R., \& Milanov, H. (2010). It's the connections: The network perspective in interorganizational research. Academy of Management Perspectives. https://doi.org/10.5465/amp.2010.50304 417.

Zhou, X., Li, Q., Zhao, W., \& Cai, H. (2003). Embeddedness and contractual relationships in China's transitional economy. American Sociological Review. https://doi.org/10.2307/3088903.

Publisher's Note Springer Nature remains neutral with regard to jurisdictional claims in published maps and institutional affiliations. 